Article

\title{
Family Genealogy and Family Communication: Finding Common Ground
}

\author{
Amy M. Smith
}

Department of Communication, Salem State University, 352 Lafayette Street, Salem, MA 01970, USA; asmith@salemstate.edu

Academic Editor: Philip Kretsedemas

Received: 5 November 2016; Accepted: 15 January 2017; Published: 22 January 2017

\begin{abstract}
The intersection between family genealogy and family communication is an area ripe for scholarly research within the field of communication studies, as well as the broader area of genealogy studies. The opportunity and desire to conduct family genealogical research continues to grow as the services and tools making such research become more affordable and user friendly. In reflecting upon the ways in which genealogy research and family communication interact with one another, this article seeks to make a case for ongoing and increased scholarship regarding the impact of genealogy data upon family communication patterns, family narrative, and family identity.
\end{abstract}

Keywords: family genealogy; family communication; narrative; critical ethnography; family identity

\section{Introduction}

There are many intersections between family genealogy and family communication, making it an area of study full of rich and promising findings for scholars. The proliferation of services tied to ancestral data has grown in leaps and bounds over the past two decades, as has the public interest and participation in this hobby/interest area ${ }^{1}$ [4]. Family communication research in this increasingly popular area is needed to better understand the impact upon family communication, family narrative, storytelling, and identity.

Although the types of family genealogy data collected are often quite similar, there is a great deal of variation amongst hobby/amateur genealogists with regard to the time, energy, and financial resources available to collect said data. For some, the effort begins and ends with using an online database service to search and record documents related to ancestors in the family tree. Others travel to national or international destinations, hoping to find family documents in courthouses, libraries, and cemeteries [5]. Often, when the opportunity is available to interview older family members, genealogists work to record and preserve the oral history of the family. The task of managing the family story frequently falls to the elder generations [6], who also make efforts to preserve family documents, photos, and stories as best they are able. As a communication scholar who also has an interest in locating my own family genealogy data, I find myself with an interesting perspective to understand how this data influences and shapes family communication.

\section{Discussion}

There are many definitions of family within modern society, but for the purposes of genealogical data, family most often means those located somewhere within the family "tree," or network.

1 In September 1999, Ancestry.com reported 880 unique visitors [1]. By comparison, in March 2007, the same site reported 4.5 million unique visitors [2]. Ancestry.com is the largest online family history site, with over 2 million subscribers. AncestryDNA, the genetic testing service of Ancestry.com, reported testing on 1 million people as of 2015 [3]. 
Family communication theorists most often define family as either nuclear/immediate, or extended. Kinship is a useful concept to call upon when considering the definition of family. Johnson ([7], p. 625) defines kinship as "social relationships among those related by blood, marriage, or self-ascribed association that extend beyond the marital [sic] dyad, the nuclear family of parents and dependent children, or one-parent households." Scodari cautions against allowing kinship to "facilitate hegemonic meanings in texts and practices of family history" and goes on to discuss the perils of taking a strictly genetics-driven approach to defining kinship ([8], pp. 54-55) which often discounts the interpersonal relationships people have with one another.

\subsection{Storytelling}

Using a blend of family narratives, artifacts, and experiences, families work to shape both individual and family identities. Storytelling is an integral component in the construction of these identities. Jorgenson and Bochner [9] list four ways in which stories are useful in family communication: first, stories are a means for family members to perform and transform their identities; second, stories are a demonstration of family values, beliefs, desires, and aspirations; third, stories are canonical (courtship stories, birth stories, survival stories); and finally, stories are evocative when they come from the margin (margin stories often resist canonical status). Family genealogy research utilizes, at minimum, the facts that relate to these types of canonical stories, such as birth, marriage, and death records. However, for many family genealogists, the real payoff is finding information that tells stories from the margins, such as those details surrounding family secrets, for example, an unplanned/unwed birth story or an interracial marriage. Stories from the margins might include family migration journeys or day-to-day experiences. These margin stories provide the family genealogist with rich and vivid descriptions about their ancestors, but may also provide the family communication scholar a way to blend personal narrative with scholarly theory.

Family researchers not only interpret the family story, but also hold up images of the family [9]. These idealized images are fueled by the strong reliance upon names and dates, and the lack of margin stories within family genealogy research. Understanding the ways in which family stories are used within family communication is crucial to recognizing individual and family communication patterns and structures.

\subsection{Memory}

A crucial factor in the recording of family genealogical data is memory or recall. When utilizing family memories as a site for research, accuracy becomes a valid concern. Memories may fade, become altered, or be contested by others with conflicting recollections. Research that relies upon memories, however, should focus less on accuracy and more upon the impact of the memory upon the individual or family. Bochner and Ellis [10] argue that the question regarding the accuracy of memory should not be "how is it true," but rather "how is it useful?" Denzin [11] reinforces this sentiment, arguing that telling the "emotional truth," getting to the deeper meaning behind the memory is more important than factual accuracy. Memory can have a powerful impact upon family story, and may be useful when working through challenging events [12]. Over time, the family identity relies more heavily upon these memories as they evolve into shared family stories.

Being able to contextualize the event which a memory/story is based upon is another key component for family researchers [13]. Having an understanding of the time and place the event occurred is crucial for reframing the memory in a way that articulates any injustices or oppression within specific historical periods [14,15]. This allows the events to be understood not only in the moment, but also as to how they may become useful as a site for research.

\subsection{Research Methodologies}

Although there are multiple research methodologies utilized within the field of family communication, I would like to focus specifically on critical methodologies here, as there is often a lack 
in these types of studies within the field. In his work surveying 1254 family communication studies, Stamp [16] found that most family communication research is conducted utilizing empirical methods of inquiry $(91.87 \%)$. Interpretive methods of inquiry comprised $6.46 \%$ of these studies, while studies utilizing critical methods of inquiry made up only $1.67 \%$. The benefit(s) of critical methods of inquiry are that they provide space and voice to the lived experience and narrative of both the subject and the researcher. This allows for richer texts that go beyond statistical data.

Critical ethnography is the first of these methods that I would like to address. Critical ethnography is sometimes described using other terms, such as performance ethnography [11], new ethnography [17], and feminist ethnography [18]. The common theme that links these together is the positionality of the researcher with the subject. Critical ethnographers must recognize how their own actions, behaviors, and descriptions are acts of domination, thus calling into question the ethics of representation in ethnographic research [19].

Working to address these issues, Madison asks researchers to "contextualize their own positionality" in such ways so that it is evident and open to judgment and evaluation. She states, "we are not simply subjects, but we are subjects in dialogue with the Other" ([20], p. 9). Clair ([21], p. 15) offers similar concerns when discussing the choices researchers make regarding language selections. She states, "Communication and language are never neutral. Communication can be oppressive an act as a means of silencing different groups of people. However, communication also carries with it the possibilities for emancipation."

Utilizing critical ethnography as a method of inquiry demands that researchers understand both the doing of lived experience and the context of those experiences within a particular location [11,22]. Jones describes critical ethnography as "asking questions about what experience means to us-now and over time" ([23], p. 21). Critical ethnography works to examine injustice(s) and disrupt them by revealing the hidden power and control loci [20]. This can be accomplished through the bringing to light of marginalized voices that are often silenced in the stories.

\subsection{Lived Experience}

Family communication research is also enhanced when family narratives are collected and examined. Bochner [24] describes these studies as the examination of individual or group stories regarding that person or group's lived experiences. Narratives are often focused on an event which is meaningful to the story-holder, and may be useful in understanding how reality is constructed within the circumstances surrounding that event. Development of ideas regarding relational identity and/or issues of morality may also play a role in these narratives [25].

Narrative coherence is often created and sustained through the sharing of narratives, or stories. Coherence is used as a tool to battle the uncertainties and unexpected detours in the road [9]. Communication, Peterson and Langellier argue, is storytelling. Communication is not only about performing something (poiesis), but also about doing something (praxis). This "doing" is represented in storytelling [26]. Within family genealogy research, the stories often reveal themselves as the family data is discovered and verified.

When utilizing these types of methodologies, scholars must reflect upon their own experiences. Autoethnography, or the theorizing of personal experience, allows researchers to investigate their own stories [27]. Understanding these experiences from both an individual and cultural viewpoint will allow better understanding of the role we play in constructing the world in which we live. Researchers must understand ourselves in connection with others around us. This is essential when investigating the ways in which we are impacted and shaped by our own family interactions [28]. "Personal narratives are stories about authors who view themselves as the phenomenon and write evocative narratives specifically focused on their academic, research, and personal lives" [29].

One way to organize our lived experiences is to examine them through the lens of the narrative paradigm [30,31]. Understanding which stories get selected, along with the meaning behind them, gives researchers key insight into the ways in which story functions within family narratives. 
Arguing that people are storytellers by nature, Fisher states that all communication is story-based. People tend to seek out stories that make sense and are true to our own beliefs and values. We create our own world by carefully selecting and crafting the stories we tell, which ultimately creates and maintains our individual identity. Families function much like individuals in this regard, choosing which stories get told and retold, as well as selecting who within the family gets to do so. Through this practice a family culture is created, allowing family members to understand who they are within the family, as well as how that role impacts, and is impacted, by other family members.

In their argument to classify genealogy, family history, and biography as family narrative, Langellier and Peterson ([32], p. 56) state, "family narratives emerge more fragmentarily, circumstantially, and promiscuously than is suggested by the deliberate, continuous, and complete flavors of these terms." Arguing that family genealogy is a term that limits the function of family story, they go on to discuss the performative nature of family culture as a strategic process that calls the family into being. Story is a critical part of family communication, serving several functions such as historical marker, guide to values and beliefs, and model of appropriate communication techniques [33]. These stories allow researchers insight into how communication patterns are developed and maintained within and across families, often crossing cultural and socio-economic boundaries.

When researching family genealogy and family narrative, it becomes necessary to look not only at how the story/data functions within the family, but also at how the story(ies) get passed down from generation to generation. Building on Fisher's [30] concept of homo narrans, or humans as storytellers, Goodall $[34,35]$ introduces the idea of narrative inheritance. This, he explains, is the handing down of family story as a way for individuals to understand family rituals and culture. When the inherited narratives are complete they become part of the family history, but when they are incomplete they become the receiver's responsibility to finish. In his later research, Goodall [36] takes this concept further, discussing the role of researcher as storytelling where it intersects with self-presentation. He is careful not to play the hero within the family, but rather seeks to understand his own role and responsibilities within the family context before turning a critical eye toward others. Entering the examination of family narrative through one's own story is often the best place to start [34]. Researchers, however, must not only reflect on their own actions and experiences, but also have a clear understanding of how they may impact others when sharing their experiences [37]. As the story gets shared throughout the family history, identities are created and sustained. With each telling, an opportunity to re-package the data is possible. Each time the story is both retold and reconceived it gains and loses significance from the giver and the receiver [33].

\subsection{Impact Upon Family Communication}

As a family genealogy scholar, I have been able to see the impact of sharing this data within my own research [33]. According to study participants, the influence of family genealogy is mostly positive, creating new bonds and strengthening existing ones throughout the family. It is, however, possible for genealogical data to negatively impact family communication if the data reveals information the family members would prefer to disavow or wish they had never known.

In my book, Tracing Family Lines [33], I explore some of these concepts with the research participants. Each person I interviewed was passionate about recovering the data that tells her family story, and each person shared with me challenges they felt when conducting genealogy research and the reasons they were motivated to overcome those challenges. For many of the participants, there was a feeling of caring for their families by collecting and sharing the data with them. "In sharing this information with her family, the women explained, they were passing along the gift of knowing those who came before them. It is through this process of $\mathrm{K} /$ knowing that each woman came to better understand not only her family, but also herself" ([33], p. 149). This desire to both understand and share the family story reflects the values that Fisher $[30,31]$ discusses as part of the narrative paradigm, as well as Goodall's [34,35] need to "finish" the story for her family members. 
When asked to discuss the impact genealogy data has had upon their family communication, the participants cited mostly positive interactions with family members. Some said the data gave them a starting place to connect with extended family with whom they might not otherwise interact. Others, however, did provide specific examples of instances where the data had a negative impact, such as when the data did not support the existing family story or identity. It is not uncommon for genealogy researchers or family members to be disappointed or conflicted when the data reveals family situations that were historically commonplace, such as slavery, but no longer acceptable in modern times $[4,8]$. Conflict was also noted with regard to how and with whom the genealogy data was collected, as well as who was included in it. Some participants discussed feeling frustrated when their family members did not provide them with family data as requested, and/or when the efforts of the genealogy researcher appeared to be unappreciated.

Interview participants felt that they were contributing to the family narrative by seeking and recording the family data, thereby creating something new [38]. These facts, as discussed above, are often centered upon canonical family stories such as births, marriages, and deaths. However, most of the participants expressed how accomplished they felt when they also found the "meat" of the story behind those facts, along with other stories from the margin, or "existential turning points" ([9], p. 527). These stories often get left out because they are unique, rather than universal, but their exclusion can make it difficult to navigate the creation and maintenance of the family identity.

\section{Conclusions}

My research [33] was designed in response to Combs's call for ethnography to serve as a metaphor for family genealogy research [39]. Combs argues that when genealogists restrict themselves to only collecting name, date, and location data, they are removing the social relationships that bind the family/genealogical structure. "Understood as an ethnographic enterprise, genealogy can offer much insight regarding how a family and its members experience themselves, both now and in the distant

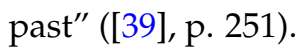

As previously discussed, the desire and opportunity to conduct family genealogy research continues to grow with the proliferation of research tools available to amateur hobbyists. The intersection of family communication and family genealogy narratives is one that will remain an area worthy of scholarly research such that we may continue to understand the ways in which genealogy data shapes and sustains family communication patterns, family narrative, and family identity.

Conflicts of Interest: The author declares no conflict of interest.

\section{References}

1. Metcale, Julian. "Family tree sites take root on the web." Brandweek, 15 November 1999, p. 50.

2. “Ancestry.com 2007 Media Kit." Available online: http://tgn.mediaroom.com/file.php/252/2007+Ancestry. com+Media+Kit.pdf (accessed on 26 March 2008).

3. "About Ancestry, Our Story." Available online: http://www.ancestry.com/corporate/about-ancestry/ourstory (accessed on 20 October 2016).

4. Scodari, Christine. "Roots, Representation, and Resistance? Family History Media \& Culture through a Critical Lens." The Journal of American Culture 36 (2013): 206-20.

5. Birtwistle, Moira. "Genealogy tourism-The Scottish market opportunities." In Niche Tourism: Contemporary Issues, Trends, and Cases. Edited by Marina Novelli. Oxford: Elsevier Butterworth-Heinemann, 2005, pp. 59-72.

6. Kornhaber, Arthur. Contemporary Grandparenting. Thousand Oaks: Sage Publications, 1996.

7. Johnson, Colleen L. "Perspectives on American kinship in the later 1990s." Journal of Marriage and the Family 62 (2000): 623-39. [CrossRef]

8. Scodari, Christine. "Recuperating Ethnic Identity through Critical Genealogy." Journal of Multidisciplinary Research 8 (2016): 47-62.

9. Jorgenson, Jane, and Arthur P. Bochner. "Imagining Families through Stories and Rituals." In The Handbook of Family Communication. Edited by Anita Vangelisti. Mahweh: Lawrence Earlbaum, Inc., 2004, pp. 513-38. 
10. Bochner, Arthur. P., and Carolyn Ellis. "Introduction: Talking over ethnography." In Composing Ethnography: Alternative Forms of Qualitative Writing. Edited by Carolyn Ellis and Arthur P. Bochner. Walnut Creek: AltaMira Press, 1996, pp. 13-45.

11. Denzin, Norman K. Performance Ethnography: Critical Pedagogy and the Politics of Culture. Thousand Oaks: Sage Publications, 2003.

12. Poulos, Christopher N. "The ties that bind us, the shadows that separate us: Life and death, shadow and (dream)story." Qualitative Inquiry 12 (2006): 96-117. [CrossRef]

13. Ball, Robert. "Visualizing genealogy through a family-centric perspective." Information Visualization (2015): 1-16. [CrossRef]

14. Trujillo, Nick. "In search of Naunny's history: Reproducing gender ideology in family stories." Women's Studies in Communication 25 (2002): 88-113. [CrossRef]

15. Trujillo, Nick. In Search of Naunny's Grave: Age, Class, Gender, and Ethnicity in an American Family. Walnut Creek: AltaMira Press, 2004.

16. Stamp, Glen H. “Theories of family relationships and a family relationships theoretical model." In Handbook of Family Communication. Edited by Anita L. Vangelisti. Mahwah: Lawrence Erlbaum Associates, Publishers, 2004, pp. 1-30.

17. Goodall, Harold L. Writing the New Ethnography. Walnut Creek: AltaMira Press, 2000.

18. Sanger, Pamela C. "Living and writing feminist ethnographies: Threads in a quilt stitched from the heart." In Expressions of Ethnography: Novel Approaches to Qualitative Methods. Edited by Robin P. Clair. Albany: State University of New York Press, 2003, pp. 29-44.

19. Noblit, George W., Susana Y. Flores, and Enrique G. Murillo. Postcritical Ethnography: An Introduction. Cresskill: Hampton, 2004.

20. Madison, D. Soyini. Critical Ethnography: Method, Ethics, and Performance. Thousand Oaks: Sage Publications, 2005.

21. Clair, Robin P. "The changing story of ethnography." In Expressions of Ethnography: Novel Approaches to Qualitative Methods. Edited by Robin P. Clair. Albany: State University of New York Press, 2003, pp. 3-28.

22. Conquergood, Dwight. "Performing as a moral act: Ethical dimensions of the ethnography of performance." Literature in Performance 5 (1985): 1-13. [CrossRef]

23. Jones, Stacy H. Kaleidoscope Notes: Writing Women's Music and Organizational Culture. Walnut Creek: AltaMira Press, 1998.

24. Bochner, Arthur P. "Perspectives on inquiry II: Theories and stories." In Handbook of Interpersonal Communication, 2nd ed. Edited by Mark L. Knapp and Gerald R. Miller. Beverly Hills: Sage Publications, 1994, pp. 21-41.

25. Riessman, Catherine K. Narrative Analysis. Newbury Park: Sage Publications, 1993.

26. Peterson, Eric E., and Kristin M. Langellier. "Storytelling." In Communication as ... : Perspectives on Theory. Edited by Gregory J. Shepherd, Jeffery St. John and Ted Striphas. Thousand Oaks: Sage Publications, 2006, pp. 123-31.

27. Bochner, Arthur P., and Carolyn Ellis. "Autoethnography." In Communication as ... : Perspectives on Theory. Edited by Gregory J. Shepherd, Jeffery St. John and Ted Striphas. Thousand Oaks: Sage Publications, 2006, pp. 110-22.

28. Ellis, Carolyn. "Maternal connections." In Composing Ethnography: Alternative Forms of Qualitative Writing. Edited by Carolyn Ellis and Arthur P. Bochner. Walnut Creek: Altamira Press, 1996, pp. $240-43$.

29. Ellis, Carolyn, Tony E. Adams, and Arthur Bochner. "Autoethnography: An Overview." Forum Qualitative Sozialforschung/Forum: Qualitative Social Research 12 (2010): article 10.

30. Fisher, Walter. "Narration as human communication paradigm: The case of public moral argument." Communication Monographs 51 (1984): 1-22. [CrossRef]

31. Fisher, Walter. Human Communication as Narration: Toward a Philosophy of Reason, Value, and Action. Columbia: University of South Carolina Press, 1987.

32. Langellier, Kristin M., and Eric E. Peterson. "Family storytelling as a strategy of social control." In Narrative and Social Control: Critical Perspectives. Sage Annual Reviews of Communication Research, Volume 21; Edited by Dennis K. Mumby. Newbury Park: Sage Publications, 1993, pp. 49-76.

33. Smith, Amy M. Tracing Family Lines: The Impact of Women's Genealogy Research on Family Communication. Lanham: Lexington Books, 2012. 
34. Goodall, Harold L., Jr. "Narrative inheritance: A nuclear family with toxic secrets." Qualitative Inquiry 11 (2005): 492-513. [CrossRef]

35. Goodall, Harold L., Jr. A Need to Know: The Clandestine History of a CIA Family. Walnut Creek: Left Coast Press, Inc., 2006.

36. Goodall, Harold L., Jr. Writing Qualitative Inquiry: Self, Stories, and Academic Life. Walnut Creek: Left Coast Press, 2008.

37. Ellis, Carolyn. “Telling secrets, revealing lives: Relational ethics in research with intimate others." Qualitative Inquiry 13 (2007): 3-29. [CrossRef]

38. Fulton, Crystal. "The Genealogist's Information World: Creating Information in the Pursuit of a Hobby." Journal of Multidisciplinary Research 8 (2016): 85-100.

39. Combs, Jason E. “Genealogy as an ethnographic enterprise.” In Expressions of Ethnography: Novel Approaches to Qualitative Methods. Edited by Robin P. Clair. Albany: State University of New York Press, 2003, pp. 243-56.

(C) 2017 by the author; licensee MDPI, Basel, Switzerland. This article is an open access article distributed under the terms and conditions of the Creative Commons Attribution (CC BY) license (http:/ / creativecommons.org/licenses/by/4.0/). 